\title{
Results of Dynamic Interlock Nailing in Distal Tibial Fractures
}

\author{
Wasudeo Gadegone*, Yogesh Salphale, Vijayanand Lokhande \\ Department of Orthopaedics \& Traumatology, Chandrapur Multispeciality Hospital, Chandrapur, India \\ Email: gadegone123@yahoo.co.in
}

Received 22 April 2015; accepted 19 July 2015; published 22 July 2015

Copyright (C) 2015 by authors and Scientific Research Publishing Inc. This work is licensed under the Creative Commons Attribution International License (CC BY). http://creativecommons.org/licenses/by/4.0/

(c) (i) Open Access

\section{Abstract}

A study was performed in adults to determine the efficacy of closed reduction and intramedullary nailing in dynamic mode on union, implant failure and incidence of malalignment in patients who sustained an extra-articular fracture of the distal tibia. Methods: Between January 2007 and December 2013, one hundred and twelve patients of distal tibia that involved the distal $6 \mathrm{~cm}$ of the tibia were treated at our hospital with reamed intramedullary nailing with use of two distal interlocking screws and one proximal screw in dynamic mode. The augmentation was done with poller screws whenever it was necessary. The nailing of fibular fractures was done in 27 cases. There were 85 males and 27 females with a mean age of 30.9 (range: 20 to 72). Eighty fractures were closed whereas 32 were grade 1 open fractures. Results: The average time to union of the closed fracture was 15.4 weeks (range: 12 - 28 weeks). The healing times for the primarily nailed compound Grade I averaged 17.8 (range: 15 - 34 weeks). After minimum follow-up of one year, rate of primary union was in $97.32 \%$. One case of broken nail required revision surgery. There were three cases of delayed union and two cases of non union. In one case there was deep infection which required exchange nailing with antibiotic impregnated nail. There was breakage of interlocking screws in three cases but fracture had united. In twenty two cases acceptable malalignment of the tibia was observed after union. The outcome was determined at a minimum of one year in our study based on the criteria of Johner and Wruhs. Out of 112 patients, 79 patients had excellent results, 29 had good results and 4 had fair results. Conclusions: The dynamic osteosynthesis of distal tibia by interlocking nail and judicious use of poller screws is an effective alternative for the treatment of distal metaphyseal tibial fractures.

\section{Keywords}

Distal Tibial Fractures, Interlocking Nail, Dynamic Osteosynthesis, Poller Screws, Screw Intramedullary Nail

\footnotetext{
${ }^{*}$ Corresponding author.
} 


\section{Introduction}

The fractures of distal tibia-fibula are relatively common because of increased road traffic accidents. The majority of these fractures occur because of high energy trauma. The surgical treatment of distal tibial fractures remains controversial because of the limited soft tissue, blood supply and increased risk of infection, delayed union or nonunion [1].

Open reduction and plating is a popular method that can result in good fixation. The technique is used widely, but it usually requires a relatively extensive wound exposure and soft-tissue dissection and is often associated with delayed healing, infection, and hardware problems [2] [3].

Recently, minimally invasive percutaneous medial locked plating has been described in the literature with promising results [4] [5]. However, this method is technically demanding, and it is often difficult to achieve anatomic reduction of the fracture site and if fixation of the fibula is required; an additional incision must be made on the lateral side. Locked intramedullary (IM) nailing is the treatment of choice for closed fractures of the tibial shaft. In distal tibial fractures it is often difficult to achieve and retain good reduction by nailing methods. The nail does not fit properly into the distal fragment of the tibia. This places additional stress on the distal locking bolts and may lead to breakage and mal-alignment [6] [7].

IM nails currently represent an effective approach to the treatment of complex tibial fractures such as distal tibial metadiaphyseal fractures [8] [9]. The low multidirectional locked nailing may represent a superior surgical option, since it offers advantages in terms of mean operating time, hospital stay, full weight-bearing time and union time [10] [11].

The aim of this paper is to evaluate dynamically locked IM nails with the judicious use of Poller screws (blocking screws) and fibular fixation as a supplement to stability and optimal alignment for closed and type I open extra-articular distal tibial fractures within $6 \mathrm{~cm}$ of the ankle joint.

\section{Materials and Methods}

A prospective study of 112 patients who sustained an extra-articular fracture of the distal tibia was performed between January 2007 and December 2013. Biplanar injury radiographs were evaluated to determine the fracture location and involvement of the distal part of the tibia. Inclusion criteria for this retrospective review were acute extraarticular fractures in skeletally mature persons, involving the distal $6 \mathrm{~cm}$ of the tibia, treated with an IM nail. In this series cases with distal fragment of at least $3 \mathrm{~cm}$ in length that allowed placement of at least two interlocking screws through the nail are included.

Eighty fractures were closed and 32 grade I open fracture. Exclusion criteria for this study were severe open fractures (Gustilo-Anderson grade II and III) and fractures with intraarticular extension. There were one hundred and twelve patients ( 85 males; 27 females) with a mean age of 30.9 years (range: 20 to 72 ) with spiral and oblique fractures of distal tibia were seen more frequently. An associated fracture of the fibula was present in one hundred and-five patients. In 27 cases fibula was at the same level.

The mechanisms of injury included fall from height (thirteen patients) motor vehicle accident (thirty-nine patients), sports injury (twenty-six cases) and simple falls (nineteen cases) (Table 1).

According to the AO/OTA guidelines, there were fifty nine $43 \mathrm{~A} 1$, thirty $43 \mathrm{~A} 2$ and twenty three $43 \mathrm{~A} 3$ fractures [12]. Three fracture with associated medial malleolus fracture and two cases of minor coronal split were included in study.

The distal tibial nail used in this study has a modification at the distal end. The two distal interlocking holes in distal end are at right angles to each other. The most distal interlocking hole is $5 \mathrm{~mm}$ proximal to distal end of

Table 1. Type A fracture: extra-articular fractures with subtypes A1 (simple), A2 (wedge), and A3 (complex) The site of fractures.

\begin{tabular}{cccc}
\hline Site of Fracture & Patients No. & Males No. & Female No. \\
\hline Distal tibial fractures & 112 & 85 & 27 \\
A1 & 59 & 44 & 15 \\
A2 & 30 & 24 & 6 \\
A3 & 23 & 17 & 6 \\
\hline
\end{tabular}


the nail and is in anteroposterior direction and proximal distal interlocking hole is in mediolateral direction i.e., at right angle to distal interlocking hole at $15 \mathrm{~mm}$ from the tip of the nail. After admission, routine inpatient investigations were performed on all patients to evaluate their fitness for surgery. The nailing was done under spinal anesthesia on a fracture table. The hip was flexed to $45^{\circ}$ and knee up to $60^{\circ}$ with a well-padded bolster kept away from the popliteal fossa to avoid pressure on the popliteal vessels. Manual traction is given by the assistant.

Reduction was done and checked in anteroposterior and lateral views on the image intensifier. In thirty cases, fibular length was achieved by traction; reduction was obtained and stabilized by retrograde screw IM nail. The $\mathrm{K}$ wires were used as a joystick for reduction in some of the cases. In 5 cases limited open reduction is required to pass a nail in fibula. A fibular plate was used as a primary reduction aid to obtain length, alignment, and rotation of the distal tibial segment in three patients where lateral malleolus is fractured. Undisplaced medial malleolar fracture was encountered in three cases fixed by screws after interlocking nailing.

A $2.5-\mathrm{cm}$ incision was made in the midline at the upper end of the tibia just adjacent to the patellar tendon on the medial aspect. The patellar tendon was retracted laterally. The entry point of the nail was marked with a curved awl and the medullary cavity was reached gradually. The guide wire was passed after reduction ensuring its position in the center of the distal tibial metaphysis. The position of guide wire was improved by use of poller screws. The reaming of the canal was done up to isthmus. The appropriate nail was passed over the guide wire and checked under the image intensifier till the tip anchors into the distal tibial metaphysis. In most cases the length of the nail was selected such that it extends to within $1.5 \mathrm{~cm}$ of the distal joint line in the antero posterior view and flush with the entry point in the proximal end in the lateral view.

The stability was assessed. In cases where we felt that distraction was likely or was seen on the image intensifier, gentle thumping of the heel with the knee flexed and fracture stabilized by the assistant helped to bring the fragments in good apposition. Limited open reduction was required in 12 patients. Proximal locking was done in a dynamic mode through aiming device and distally locked with $4.9 \mathrm{~mm}$ screws in two planes within 2 $\mathrm{cm}$ of the articular surface of the tibia. The biplanar distal interlocking screws passed through the distal end of the nail at $5 \mathrm{~mm}$ to $15 \mathrm{~mm}$ from the tip (Figure 1 and Figure 2).

The unstable distal meta-diaphyseal fractures were stabilized with a poller screw in 38 cases. Poller screws are used in 23 cases on medial side, 12 cases on lateral side and 3 cases on posterior side of the nail (Figure 3). Washer is used in five cases on medial side when there was comminution at screw insertion site.

The mean time for the surgery was $48 \mathrm{~min}(35-65 \mathrm{~min})$ and the average hospitalization time in our cases was 5 days ( 3 - 12 days). Polytrauma patients underwent surgery, once they were hemodynamically stable and declared fit for surgery by attending physician. IM nails of size $9 \mathrm{~mm}$ were used in 68 cases and size $10 \mathrm{~mm}$ in 44 cases. The nailing of the fibula was carried in thirty cases by screw IM nail where we felt that the distal tibial fragment was unstable. Two of the cases had compartment syndromes, which required immediate fasciotomy on

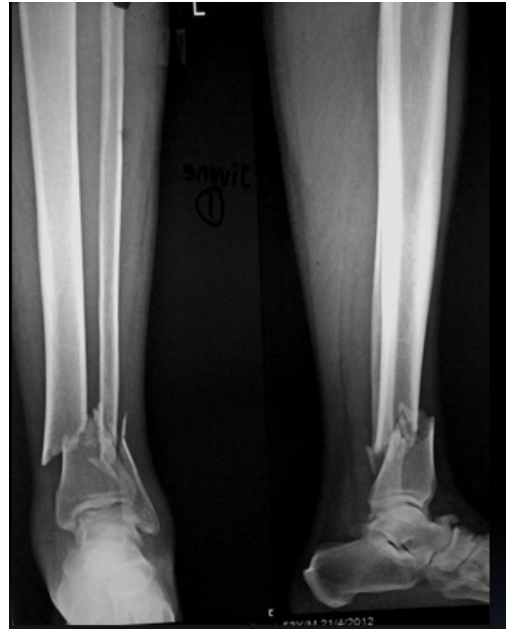

(a)

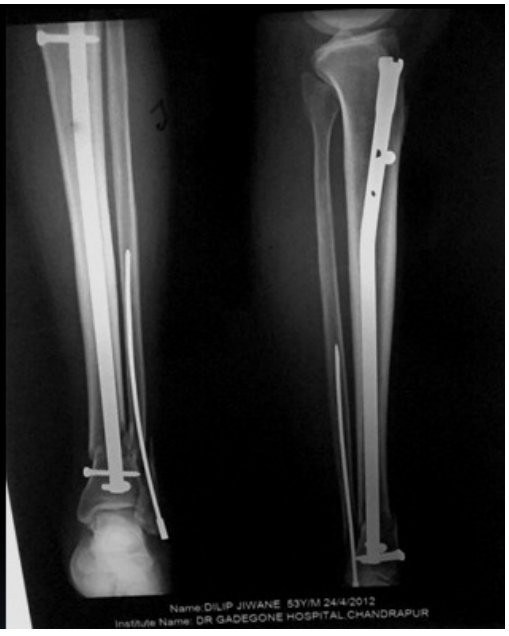

(b)

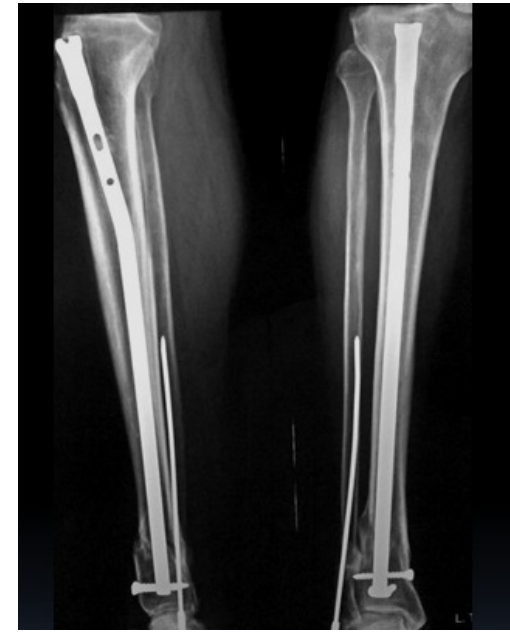

(c)

Figure 1. A 36-yr-old female with distal tibial fracture. (a) Preoperative X-ray Ap and lateral; (b) Postoperative X-ray showing fibula fixation with screw intramedullary nail and tibia with interlocking nail; (c) Good union with 15 months' follow-up of interlocking nail and screw intramedullary nail for fibula. 


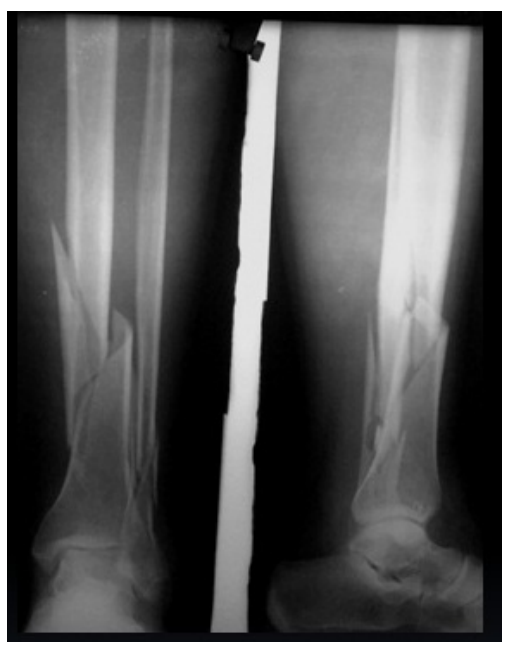

(a)

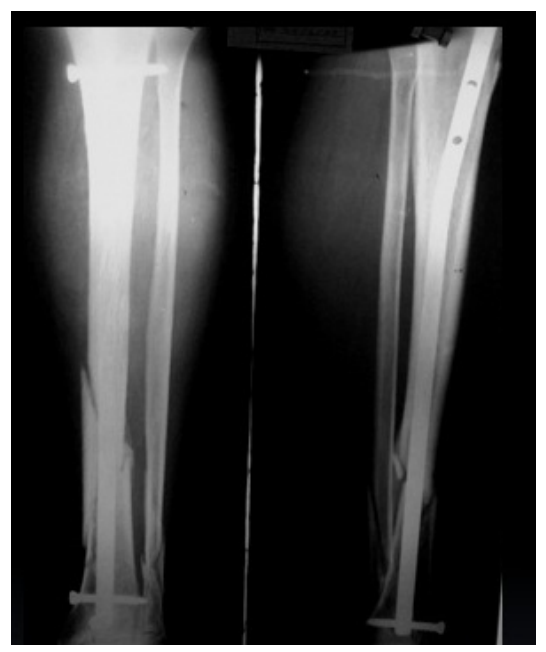

(b)

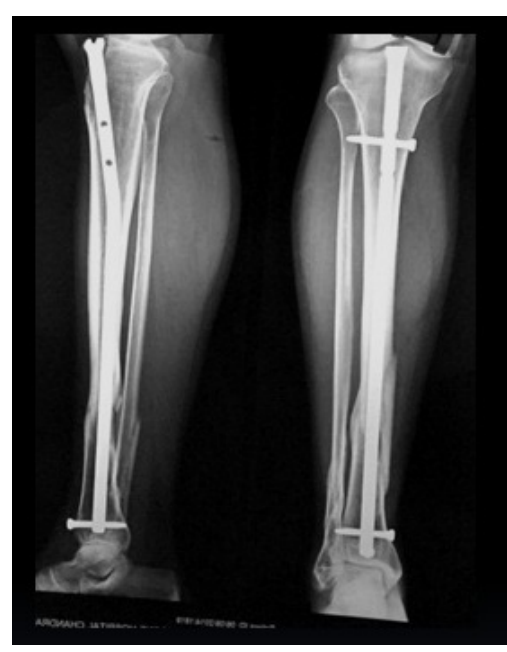

(c)

Figure 2. A 58-year-old patient with fresh fracture distal tibia-fibula. (a) Preoperative AP and lateral radiograph; (b) Postoperative X-ray showing interlocking nail; (c) At 18 months latest follow up, fracture have united well.

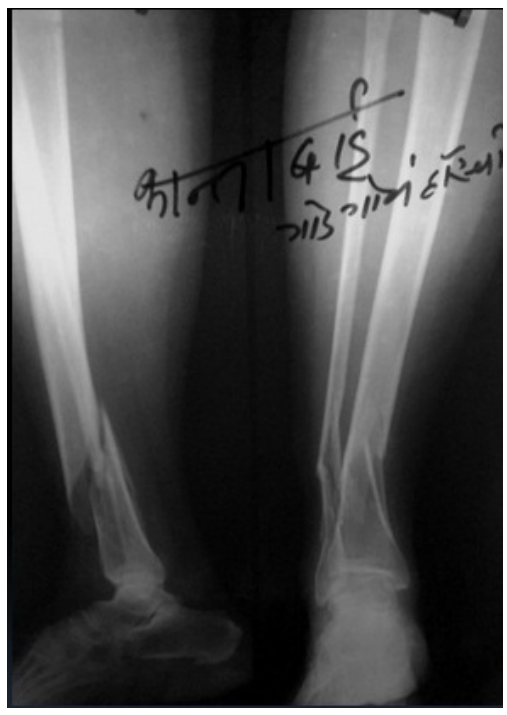

(a)

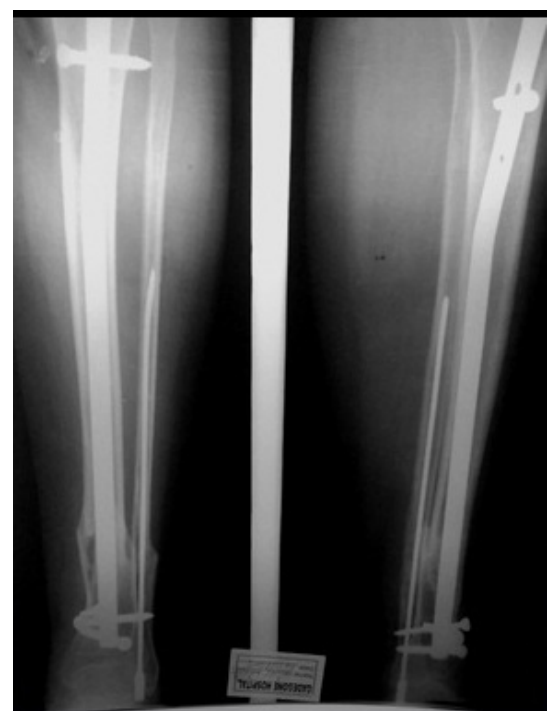

(b)

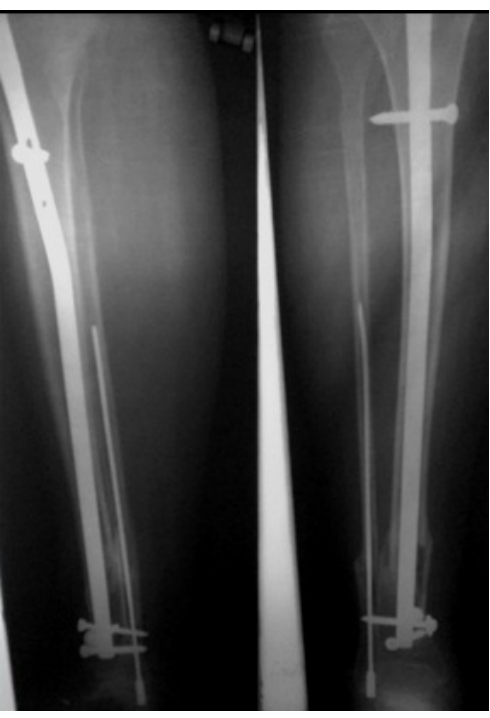

(c)

Figure 3. A 32-year-old male patient presented fresh fracture of distal tibia-fibula. (a) Preoperative AP and lateral radio-graphs; (b) Fixation of tibia with nail and fibula with screw intramedullary nail and use of poller screw; (c) Fracture well united in 14 weeks post op as seen from this radiograph with use of poller screw.

the third day of the surgery. All patients received antibiotic prophylaxis in the form of first generation cephalosporin that was started preoperatively and continued until the third postoperative day. All patients of A3 fracture received a short leg cast for the initial four weeks after suture removal. Patients with an extra-articular distal tibial fracture were not allowed to bear weight for six weeks.

\section{Results}

All 112 fractures in 112 patients were followed up serially at least until the time of solid union. The follow-up period averaged 15 months (12 - 26 months). Eighty eight patients were allowed partial weight-bearing by 6 weeks after operation. 20 patients, type $\mathrm{C}$ (most unstable) fractures, partial weight-bearing was begun when the fracture was stable to axial and rotational load at 8 weeks ( $6-10$ weeks) period. The average time to full weight-bearing was 8.2 weeks. The fracture was assessed for union at the follow up examinations. Absence of 
pain at the fracture site and radiographic evidence of callus in anteroposterior and lateral views of two or more cortices was considered as healed. The average time to union of the closed fracture was 15.4 weeks (range, 12 30 weeks) and for primarily nailed compound Grade I averaged 17.8 weeks (range 15 - 40 weeks) respectively (Figure 4). Non-union was seen in 2 cases and additional procedure of bone grafting was done. In one case there was deep infection requiring removal of nail. Antibiotic impregnated nail is implanted. Infection healed and union occurred after ten months of follow up. There were three cases of delayed union lead to breakage of interlocking screws. In one case union developed after breakage of dynamic locking screws. Other two cases developed distal screw breakage probably because of the early weight-bearing, but the fractures healed uneventfully. There was one nail breakage after three months of follow up. This case successfully revised with exchange nail and uneventful union occurred in eight months. Twenty two patients had a malalignment of the tibia but after union it was within acceptable range. They attained the full function of ankle and knee. Superficial infection occurred in five cases, three of which were on the nail entry portal whereas two were at the distal locking site. They were treated successfully with debridement of the wound and antibiotics.

Return of a functional range of motion in the knee was full as measured at the latest clinical visit at one year follow up in one hundred eight In twenty nine cases at least $80 \%$ of the range as compared to uninjured side loss of range of ankle motion and pain were observed in earlier period of follow up. Although pain was resolved in all cases after rehabilitation and no limitation of daily activity was found in these cases. Four patients had significant loss of dorsiflexion and plantar-flexion. For alignment measurement anteroposterior and lateral radiographs were made from both legs. Shortening more than $1 \mathrm{~cm}$ was considered significant. Malalignment was defined as $>5^{\circ}$ varus/valgus deformity, $>10^{\circ}$ procurvatum/or recurvatum or $>10^{\circ}$ rotation.

The fracture healed in varus angulation in seven cases. The angle ranged from $5^{\circ}-10^{\circ}$ (mean, $6^{\circ}$ ), the fracture healed in valgus angulation $6^{\circ}-8^{\circ}$ in twelve cases and in three cases, we could see the recurvatum deformity but malalignment was under physiological limits and the patients presented at the routine clinicoradiological review. But that did not affect the functional demands of the patients.

Seven patients of comminuted fractures had a shortening of $1 \mathrm{~cm}$. sixteen patients had less than $1 \mathrm{~cm}$ of shortening ranging from $5-8 \mathrm{~mm}$. The proximal migration of the nail was seen in 23 cases due to dynamization. Eleven patients reported anterior knee pain. Three patients required early removal of nail for pain and persistent irritation at the knee after union. Two patients of nonunion of fibula was noticed after one year follow up but functionally there was no problem to the patients. After average follow up of nine months ( 7 months- 18 months) the results were graded according to the criteria laid down by Johner and Wruhs. Our results were excellent in 79 cases (70.54\%), good in 29 cases (25.90\%), and fair in 4 cases (3.56\%) (Table 2).

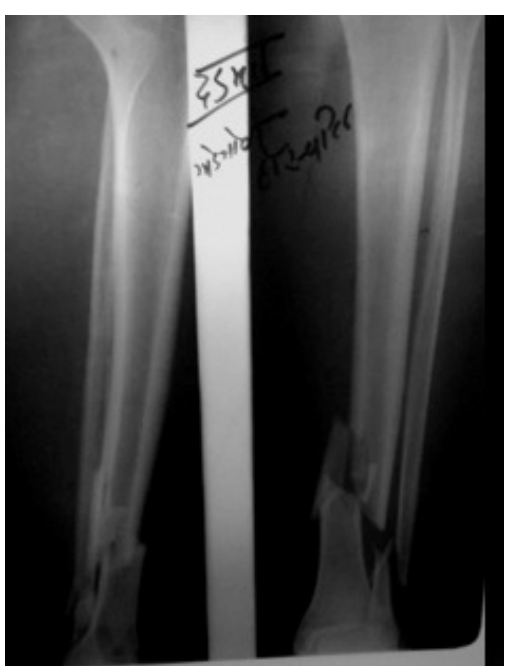

(a)

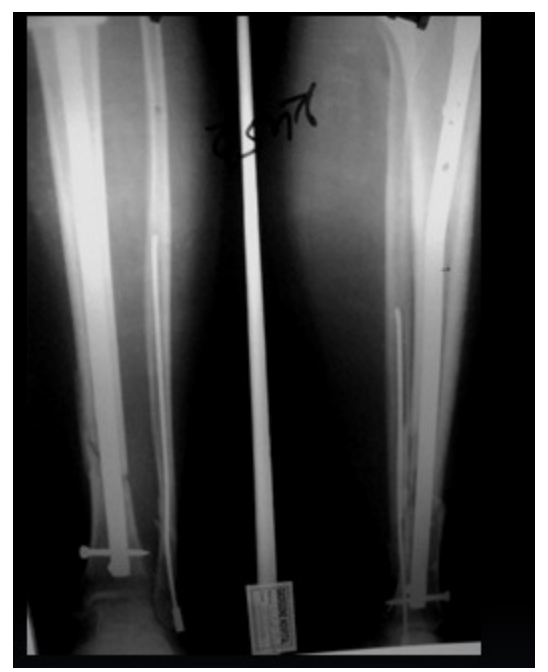

(b)

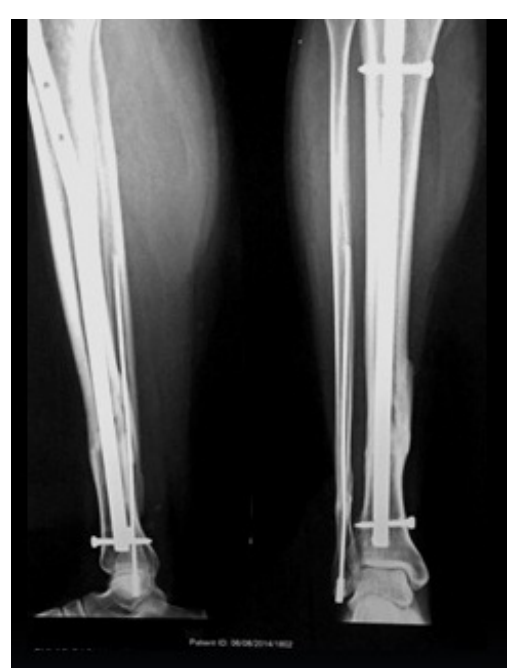

(c)

Figure 4. A 62-year-old female patient presented fresh fracture of distal tibia-fibula. (a) Preoperative AP and lateral radio-graphs; (b) Postoperative X-ray after one month follow-up with use of poller screw to fix coronal split; (c) Fracture well united. 1 year 4 months follow-up as seen this radiograph. 
Table 2. The results in our study based on the criteria of Johner and Wruhs [13].

\begin{tabular}{|c|c|c|c|c|}
\hline Criteria & Excellent & Good & Fair & Poor \\
\hline Non-union/infection & None & None & None & Yes \\
\hline NV Injury & None & Minimal & Moderate & Severe \\
\hline \multicolumn{5}{|l|}{ Deformity (in degree) } \\
\hline Valgus/varus & None & $2-5$ & $6-10$ & $>10$ \\
\hline Pro/recurvatum (in degree) & $0-5$ & $6-10$ & $11-20$ & $>20$ \\
\hline Rotation & $0-5$ & $6-10$ & $11-20$ & $>20$ \\
\hline Shortening & $0-5 \mathrm{~mm}$ & $6-10 \mathrm{~mm}$ & $11-20 \mathrm{~mm}$ & $>20 \mathrm{~mm}$ \\
\hline \multicolumn{5}{|l|}{ MOBILITY } \\
\hline Knee & Full & $80 \%$ & $>75 \%$ & $>75 \%$ \\
\hline Ankle & $>75 \%$ & $>75 \%$ & $>50 \%$ & $<50 \%$ \\
\hline Subtalar & None & $>50 \%$ & $<50 \%$ & \\
\hline Pain & None & Occasional & Moderate & Severe \\
\hline Gait & Normal & Normal & Mild limp & Significant \\
\hline Sternous activities & Possible & Limited & Severe restriction & Impossible \\
\hline Results (n) & $79(70.54 \%)$ & $29(25.90 \%)$ & $4(3.56 \%)$ & 0 \\
\hline
\end{tabular}

\section{Discussion}

The management of unstable distal tibial fracture remains challenging. The optimal treatment of unstable tibial fracture without articular involvement remains controversial. A variety of treatment methods have been suggested for distal tibial fractures. The intramedullary nailing and plate fixation represent two viable approaches to internal fixation of extra-articular fractures of the distal tibia. It is still a matter of debate whether tibia diaphyseal fractures should be treated by plate or nail. The open reduction and plating results in extensive soft tissue dissection and may be associated with wound complications. Distal tibia has less vascular and soft tissue support than any other part of the tibia therefore infection, delayed union or non-union have been a more common complications after open reduction and internal plate fixation [2] [14].

The fixation of distal tibial fractures with new nail system or anatomically contoured locking compression plate in association with use of the Minimally Invasive Plate Osteosynthesis (MIPO) technique is associated with high union rates and offers a significant benefit in protecting the soft tissue enveloping the fracture site. Although both techniques have demonstrated success in maintaining reduction and promoting stable union, they possess distinct advantages and disadvantages that require careful consideration during surgical planning. Differences in soft-tissue health and construct stability must be considered when choosing between intramedullary nailing and plating of the distal tibia [15] [16].

IM nailing can be considered the "gold standard" for the treatment of tibial midshaft fractures, but there are concerns about their use in distal tibia fractures [17]. This is because of technical difficulties with distal nail fixation, and the discrepancy between the diaphyseal and metaphyseal diameter of the IM canal, malalignment of the distal tibia may develop after nailing. There is a risk of nail propagation into the ankle joint, In recent years, intramedullary nailing has become widely accepted as the operative treatment of choice for tibial diaphyseal fractures. There use have been extended to fractures closer to the ankle joint. Bonnevialle et al. unreservedly propose nailing for distal leg fractures presenting $2-6 \mathrm{~cm}$ of cancellous bone above the subchondral bone [18]. Intramedullary nailing is an effective alternative for the treatment of distal metaphyseal tibial fractures. Simple articular extension of the fracture is not a contraindication to intramedullary fixation. Functional outcomes improve with time [10] [19] [20]. One of the most important reasons of delayed union and non-union is inadequate stabilization of the fracture. Duda et al. confirmed that biomechanical conditions in unreamed IM nailing of distal tibial fractures are unfavorable, because of a large axial to shear strain ratio between the bone fragments. Unreamed nailing of distal tibial fractures is associated with a rather high rate of bone healing complications and 
locking screw failure [21] [22].

We advocate isthmus reaming for nailing in distal tibia. The isthmus reaming minimizes the violation of medullary canal and provides effective bone dust for early union. Limited reaming spares cortical perfusion compared with standard reaming at the time of nail insertion [23] [24].

Different techniques to assist in reducing the fracture have been proposed. Krettek et al. used Poller screws. The principle of these additional screws is to orient the nail, preventing it from going where it should not go by reducing the metaphyseal space.

The judicious use of poller screws in unstable construct effectively stabilizes the distal tibial fracture [25]. We resorted to Poller screws in 23 cases on medial side, 12 cases on lateral side and 3 cases on posterior side of the nail to enhance the stability.

The fibula plays an important role in the mechanical stability of the ankle joint. For fractures of the distal tibia and fibula, the proportion of patients with reduction loss was significantly greater after IM nailing alone than after IM nailing and plate and screw fixation fibula. Many authors proposed fibular fixation of the fibula to assist in reducing the length and rotation of the tibial fracture. Whereas the series reported in the literature make it impossible to conclude on the need for fibular repair .Kumar et al. observed greater initial rigidity when the fibula was fixed compared to non fixed fibula. The fibular plating was recommended whenever IM nailing was used in unstable distal tibio-fibular fractures [26] [27].

The open reduction internal fixation of the fibula with plate has also shown an increased rate of wound complications. Williams et al. demonstrated a $23 \%$ incidence of wound infection at the fibular fixation site an additional incision must be made on the lateral side [28].

In view of our results, we recommend primary fixation of the fibula fracture up to the distal third of the fibula. We resorted to nailing of the fibula in 27 cases, which we thought that the stability of the distal tibial fragment was questionable. We strongly advocate nailing instead of plating for fibular fixation as advised by Weber. Fixation of the fibular fracture helped us to correct alignment of the tibia [29]. The procedure can be carried out mostly by close method.

The IM canal at distal tibia prevents intimate contact between the nail and endosteum, insertion of two distal locking screws becomes therefore more necessary. There is consensus in the literature on the need for double distal screw fixation so as to obtain better control of sagittal and frontal as well as horizontal movements by distributing stresses. It is also well documented that the placement of two distal screws increases the stiffness and strength of the bone-implant construct, thus leading to enhanced mechanical stability of the fixed fracture [30] [31]. In our series distal tibial fractures were treated with a reamed intramedullary nailing system that increases distal fixation by two distal interlocking screws passing through the distal $0.5 \mathrm{~cm}$ to $1.5 \mathrm{~cm}$ from the tip of the nail. The design of the nail allows one mediolateral and one anteroposterior screw for better stabilization of the distal fragment. Twenty two patients had a malalignment of the tibia but after union it was within acceptable range. They attained the full function of ankle and knee. The results were satisfactory even when two locking bolt were used. Only 3 cases had gross malalignment (angulation of $10^{\circ}-12^{\circ}$ valgus) and restricted movements of ankle. Only in three cases there were breakage of the screws.

Although the clinical benefit of dynamization in fresh tibial fractures is debated, the technique is generally accepted as an essential method of stimulating fracture healing in delayed and nonunions. Mosheiff et al. reported that 22 of 52 patients with distal tibial metaphyseal fractures treated with unreamed nailing required secondary procedures (e.g. dynamisation, autogenous bone grafting, fibulectomy) to progress to union [32].

Dynamic locking allows intermittent compression of the fracture site during early weight-bearing therefore incidence of screw breakage is very low as compared in the literature. Both the implants in tibia and fibula are in dynamic mode therefore our system referred as dynamic osteosynthesis. Incidence of delayed union and nonunion rate is very low as compared to reported series as we used the single interlocking bolt in dynamic mode especially in upper part and 2 locking bolts in lower end are used to secure the distal fragment. We believe that dynamization of long bone fractures has been shown to accelerate periosteal callus formation during early stages of bone healing. In addition, a more uniform callus formation is seen as a result of this controlled reduction of the fracture gap. Toe touch weight-bearing after removal of cast allows early osseous healing without fatigue, and failure of locking bolts. Fear of shortening because of dynamization and early weight-bearing has not been sustained. The anterior knee pain remains a problem with IM nailing regardless of the surgical approach relative to the patellar tendon.

Dogra, Ruiz, and Marsh reviewed 83 patients with isolated fractures of the tibial diaphysis treated primarily 
with closed, reamed intramedullary nailing. Twenty-nine patients experienced pain around the knee when resting. The cause of this symptom is still unclear [33] [34]. In our series incidence of anterior knee pain is very less as compared in the literature because of minimum trauma at insertion site and nail buried nicely in upper part of tibia.

At 12 months, 112 radiological and clinical files could be analyzed. The average time to union of the closed fracture was 15.4 weeks (range, 12 - 30 weeks) and for primarily nailed compound Grade I averaged 17.8 weeks (range 15 - 40 weeks) respectively. Non-union was seen in 2 cases and additional procedure of bone grafting was done. In one case there was deep infection requiring removal of nail. Antibiotic impregnated nail is implanted. Infection healed and union occurred after ten months of follow up. There were three cases of delayed union lead to breakage of interlocking screws. In one case union developed after breakage of dynamic locking screws. Other two cases developed distal screw breakage probably because of the early weight-bearing, but the fractures healed uneventfully. There was one nail breakage after three months of follow up. This case successfully revised with exchange nail. After reviewing ten series published on nailed distal fractures of the leg, the mean union rate was $96.7 \%(87 \%-100 \%)$ for a mean 17.7 weeks to bone union. The present study showed comparable results with reported series in literature [35].

The interlocking nail provides sufficient stability by three-point fixation at either ends and also in the diaphysis by its bony contact. We believe that to achieve uneventful union with minimum morbidity, due attention should be focused on avoiding damage to the periosteum of small bone fragments in comminuted fractures. The minimal surgical trauma and flexible fixation allow prompt healing when the blood supply to bone is maintained. The mechanically incompetent and biologically viable fragments heal around the nail to promote union and early recovery. It is our observation based upon the analysis of the patients in our series we strongly advise that the nail provides an effective implant providing stability and allowing union in simple and complex distal tibial fractures.

\section{Conclusion}

Dynamic osteosynthesis is a minimally invasive technique based on principles of limited exposure and indirect reduction methods, which avoids major soft tissue complications and shortens the length of the patient's stay in the hospital. We conclude that intramedullary nailing is a safe and effective technique for the treatment of distal metaphyseal tibial fractures.

\section{Conflict of Interest Statement}

It is here by declared that none of the authors have any financial and personal relationships with other people or organizations that could inappropriately influence (bias) this work submitted for publication in your esteemed journal and that no funding or sponsorship was received for this study.

\section{References}

[1] Blick, S.S., Brumback, R.J., Lakatos, R., et al. (1989) Early Bone Grafting of High-Energy Tibial Fractures. Clinical Orthopaedics and Related Research, 240, 21-41. http://dx.doi.org/10.1097/00003086-198903000-00005

[2] Teeny, S.M. and Wiss, D.A. (1993) Open Reduction and Internal Fixation of Tibial Plafond Fractures. Variables Contributing to Poor Results and Complications. Clinical Orthopaedics and Related Research, 292, 108-117.

[3] Wyrsch, B., McFerran, M.A., McAndrew, M., Limbird, T.J., Harper, M.C., Johnson, K.D. and Schwartz, H.S. (1996) Operative Treatment of Fractures of the Tibial Plafond. A Randomized, Prospective Study. Journal of Bone and Joint Surgery, 78, 1646-1657.

[4] Redfern, D.J., Syed, S.U. and Davies, S.J.M. (2004) Fractures of the Distaltibia: Minimally Invasive Plate Osteosynthesis. Injury, 35, 615-620.

[5] Helfet, D.L., Shonnard, P.Y., Levine, D. and Borelli, J. (1997) Minimally Invasive Plate Osteosynthesis of Distal Fractures of the Tibia. Injury, 28, 42-47. http://dx.doi.org/10.1016/S0020-1383(97)90114-5

[6] Hahn, D., Bradbury, N., Hartely, R. and Radford, P.J. (1996) Intramedullary Nail Breakage in Distal Fractures of the Tibia. Injury, 27, 323-327. http://dx.doi.org/10.1016/0020-1383(95)00228-6

[7] Nork, S.E., Schwartz, A.K., Agel, J., Holt, S.K., Schrik, J.L. and Winquist, R.A. (2005) Intramedullary Nailing of Distal Metaphyseal Tibial Fractures. The Journal of Bone and Joint Surgery, 87, 1213-1221. 
http://dx.doi.org/10.2106/JBJS.C.01135

[8] Robinson, C.M., McLauchlan, G.J., McLean, I.P. and Court-Brown, C.M. (1995) Distal Metaphyseal Fractures of the Tibia with Minimal Involvement of the Ankle. Classification and Treatment by Locked Intramedullary Nailing. The Journal of Bone and Joint Surgery, 77, 781-787.

[9] Tyllianakis, M., Megas, P., Giannikas, D. and Lambiris, E. (2000) Interlocking Intramedullary Nailing in Distal Tibial Fractures. Orthopedics, 23, 805-808.

[10] Hansen, M., El Attal, R., Blum, J., et al. (2009) Intramedullary Nailing of the Tibia with the Expert Tibia Nail. Operative Orthopädie und Traumatologie, 21, 620-635. http://dx.doi.org/10.1007/s00064-009-2010-2

[11] Li, Y., Liu, L., Tang, X., Pei, F.X., Wang, G.L., Fang, Y., Zhang, H. and Crook, N. (2012) Comparison of Low, Multidirectional Locked Nailing and Plating in the Treatment of Distal Tibial Metadiaphyseal Fractures. International Orthopaedics, 36, 1457-1462.

[12] Müller, M.E. (1991) The Comprehensive Classification of Fractures of the Long Bones. In: Müller, M.E., Allgower, M., Schneider, R. and Willenegger, H., Eds., Manual of Internal Fixation, 3rd Edition, Springer-Verlag, New York. http://dx.doi.org/10.1007/978-3-662-02695-3

[13] Johner, R. and Wruhs, O. (1983) Classification of Tibial Shaft Fractures and Correlation with Results after Rigid Internal Fixation. Clinical Orthopaedics and Related Research, 178, 7-25. http://dx.doi.org/10.1097/00003086-198309000-00003

[14] Teeny, S.M. and Wrss, D.A. (1993) Open Reduction and Internal Fixation of Tibial Plafond Fractures. Variables Contributing to Poor Results and Complications. Clinical Orthopaedics and Related Research, 108-117. http://dx.doi.org/10.1097/00003086-199307000-00013

[15] Oh, C.W., Kyung, H.S., Park, I.H., Kim, P.T. and Ihn, J.C. (2003) Distal Tibia Metaphyseal Fractures Treated by Percutaneous Plate Osteosynthesis. Clinical Orthopaedics and Related Research, 408, 286-291. http://dx.doi.org/10.1097/00003086-200303000-00038

[16] Casstevens, C., Le, T., Archdeacon, M.T. and Wyrick, J.D. (2012) Management of Extra-Articular Fractures of the Distal Tibia: Intramedullary Nailing versus Plate Fixation. Journal of the American Academy of Orthopaedic Surgeons, 20, 675-683. http://dx.doi.org/10.5435/JAAOS-20-11-675

[17] Kempf, Y., Grosse, A. and Lafforge, D. (1978) L'apport du verrouillage dans l'enclouage centro-médullaire des os longs. Revue de Chirurgie Orthopédique et Réparatrice de l'Appareil Moteur, 64, 635-651.

[18] Bonnevialle, P., Savorit, L., Combes, J.M., Rongières, M., Bellumore, Y. and Mansat, M. (1996) Intérêts de l'enclouage centro-médullaire verrouillédans les fractures distales de jambe. Revue de Chirurgie Orthopédique et Réparatrice de l'Appareil Moteur, 82, 428-446.

[19] Nork, S.E., Schwartz, A.K., Agel, J., Holt, S.K., Schrick, J.L. and Winquist, R.A. (2005) Intramedullary Nailing of Distal Metaphyseal Tibial Fractures. The Journal of Bone and Joint Surgery. American Volume, 87, 1213-1221

[20] El Attal, R., Hansen, M., Rosenberger, R., Smekal, V., Rommens, P.M. and Blauth, M. (2011) Intramedullary Nailing of the Distal Tibia Illustrated with the Expert(TM) Tibia Nail. Operative Orthopädie und Traumatologie, 23, 397-410.

[21] Duda, G.N., Mandruzzatoa, F., Hellera, M., Goldhahnc, J., Moser, R., Hehli, M., Claesb, L. and Haas, N.P. (2001) Mechanical Boundary Conditions of Fracture Healing: Borderline Indications in the Treatment of Unreamed Tibial Nailing. Journal of Biomechanics, 34, 639-650. http://dx.doi.org/10.1016/S0021-9290(00)00237-2

[22] Salem, K.H. (2013) Unreamed Intramedullary Nailing in Distal Tibial Fractures. International Orthopaedics, 37, 20092015.

[23] Hupel, T.M., Weinberg, J.A., Aksenov, S.A. and Schemitsch, E.H. (2001) Effect of Unreamed, Limited Reamed, and Standard Reamed Intramedullary Nailing on Cortical Bone Porosity and New Bone Formation. Journal of Orthopaedic Trauma, 15, 18-27. http://dx.doi.org/10.1097/00005131-200101000-00004

[24] Hupel, T.M., Aksenov, S.A. and Schemitsch, E.H. (1998) Effect of Limited and Standard Reaming on Cortical Bone Blood Flow and Early Strength of Union Following Segmental Fracture. Journal of Orthopaedic Trauma, 12, 400-406. http://dx.doi.org/10.1097/00005131-199808000-00006

[25] Krettek, C., Stephan, C., Schandelmaier, P., Richert, M., Pape, H.C. and Miclau, T. (1999) The Use of Poller Screws as Blocking Screws in Stabilising Tibial Fractures Treated with Small Diameter Intramedullary Nails. The Journal of Bone and Joint Surgery, British Volume, 81, 963-968. http://dx.doi.org/10.1302/0301-620X.81B6.10000

[26] Egol, K.A., Weisz, R., Hiebert, R., Tejwani, N.C., Koval, K.J. and Sanders, R.W. (2006) Does Fibular Plating Improve Alignment after Intramedullary Nailing of Distal Metaphyseal Tibia Fractures? Journal of Orthopaedic Trauma, 20, 94-103. http://dx.doi.org/10.1097/01.bot.0000199118.61229.70

[27] Kumar, A., Charlebois, S.J., Cain, E.L., Smith, R.A., Daniels, A.U. and Crates, J.M. (2003) Effect of Fibular Plate Fixation on Rotational Stability of Simulated Distal Tibial Fractures Treated with Intra-Medullary Nailing. The Journal of 
Bone and Joint Surgery. American Volume, 85, 604-608.

[28] Williams, T.M., Marsh, J.L., Nepola, J.V., DeCoster, T.A., Hurwitz, S.R. and Bonar, S.B. (1998) External Fixation of Tibial Plafond Fractures: Is Routine Plating of the Fibula Necessary? Journal of Orthopaedic Trauma, 12, 16-20. http://dx.doi.org/10.1097/00005131-199801000-00003

[29] Teitz, C.C., Carter, D.R. and Frankel, V.H. (1980) Problems Associated with Tibial Fractures with Intact Fibulae. The Journal of Bone and Joint Surgery. American Volume, 62, 770-776.

[30] Weber, T.G., Harrington, R.M., Henley, M.B. and Tencer, A.F. (1997) The Role of Fibular Fixation in Combined Fractures of the Tibia and Fibula: A Biomechanical Investigation. Journal of Orthopaedic Trauma, 11, $206-211$. http://dx.doi.org/10.1097/00005131-199704000-00012

[31] Gorczyca, J.T., McKale, J., Pugh, K. and Pienkowski, D. (2002) Modified Tibial Nails for Treating Distal Tibia Fractures. Journal of Orthopaedic Trauma, 16, 18-22. http://dx.doi.org/10.1097/00005131-200201000-00004

[32] Whipple, A.P., Wester, W. and Russel, T.A. (1995) Fatigue Failure in Small Diameter Tibial Nails. Clinical Orthopaedics and Related Research, 315, 119-128.

[33] Dogra, A.S., Ruiz, A.L. and Marsh, D.R. (2002) Late Outcome of Isolated Tibial Fractures Treated by Intramedullary Nailing: The Correlation between Disease-Specific and Generic Outcome Measures. Journal of Orthopaedic Trauma, 16, 245-249. http://dx.doi.org/10.1097/00005131-200204000-00005

[34] Court-Brown, C.M., Gustilo, T. and Shaw, A.D. (1997) Knee Pain after Intramedullary Tibial Nailing: Its Incidence, Etiology, and Outcome. Journal of Orthopaedic Trauma, 11, 103-105. http://dx.doi.org/10.1097/00005131-199702000-00006

[35] Ehlinger, M., Adam, P., Gabrion, A., Jeunet, L., Dujardin, F., Asencio, G. and Sofcot (2010) Distal Quarter Leg Fractures Fixation: The Intramedullary Nailing Alone Option. Orthopaedics Traumatology: Surgery Research, 96, 674-682. 